\title{
Design Optimization of a Porous Box-Type Breakwater Subjected to Regular Waves
}

\author{
Eric Joseph Pereira ${ }^{1}$, Hee Min Teh ${ }^{1,2, *}$, Lachmi Sri Manoharan ${ }^{1,3}$, and Chai Heng Lim ${ }^{4}$ \\ ${ }^{1}$ Department of Civil and Environmental Engineering, Universiti Teknologi PETRONAS, 32610 Bandar Seri Iskandar, Perak, \\ Malaysia \\ ${ }^{2}$ Center for Urban Resource Sustainability, Institute for Self-Sustainable Building, Universiti Teknologi PETRONAS, 32610 Bandar \\ Seri Iskandar, Perak, Malaysia \\ 3Jacobs Engineering Group Malaysia Sdn Bhd, Suite E-17-P2, Level 17, Block E, Plaza Mont' Kiara, No. 2, Jalan Kiara, Mont' \\ Kiara, 50480 Kuala Lumpur, Malaysia \\ ${ }^{4}$ UMR CNRS 6143 M2C, Département Géosciences et Environnement, Université de Rouen Normandie, Bâtiment Sciences et \\ Techniques, Place Emile Blondel, 76821 Mont Saint Aignan Cedex, France
}

\begin{abstract}
Breakwaters are used to suppress the energy of waves for providing shelter to coastal and offshore facilities. Very often, the conventional rubble mound breakwaters result in high construction cost and several environmental problems, such as water contamination and wave amplification in front of the structures due to severe wave reflection. One way to alleviate the above-mentioned problem is to appropriately increase the porosity of the breakwaters. This paper aims at developing the optimum design of a porous box-type breakwater comprising multiple scrapped pipelines via physical modelling approach. Herein, the best geometrical design of the breakwater under the governing factors of porosity, width and internal tube length is proposed. A series of experiments have been conducted under the influence of regular wave environment through the analysis of wave transmission, reflection and energy loss. Several geometrical design criteria were derived to maximize the hydraulic performance of the breakwater, when adopted at sites. The proposed breakwater is a reasonably good wave attenuator and anti-reflection structure as well as an effective energy dissipator.
\end{abstract}

\section{Introduction}

Coastal protection has developed over time with conventional breakwaters having high reliability and efficiency in wave dissipation. A concern by researchers however is the environmental sustainability of conventional coastal structures, due to the high requirements of raw material and significant impact to surrounding which results in permanent coastline changes to the surroundings. [1] To address these issues, modern breakwaters have been developed with inculcation of various geometries, porous materials and breakwater configurations to increase efficiencies of breakwater structures in wave dissipation.

Porosity of a breakwater significantly increases wave energy dissipation which reduces transmitted wave heights and minimizes wave reflections due to trapping and destruction of wave energy orbitals within the breakwater structure. Dissipation of energy also minimizes the impact loads on the structure and supports of porous breakwater which allows for application in locations with weak soil condition or for floating breakwaters. Porous breakwater structures are usually placed at the surface where wave energy is concentrated effectively destructing wave energy with reduced impacts to water circulation and longshore transport due to allowance for water circulations below and around the structure.

Sustainability of breakwaters in terms of materials can be achieved by reducing the usage of raw materials and reusing waste materials for the breakwater constructions. Scrap pipelines from the decommissioning of oil and gas industry have a tubular geometry and high material strength which is feasible for the construction of breakwaters. The availability of these resources close to the coastlines reduces need for logistics of materials to locations of breakwater construction. Breakwaters with pipe-like geometry have been studied previously by Shih [2]. He studied on highly pervious pipe breakwaters with unique arrangements of pipes resulting in high wave energy dissipation by the structure. The proposed porous box-type breakwater inculcates the above-mentioned pipe-like geometry in the structure and will be analyzed based wave energy reflection, transmission and loss with variations in porosity, tube length and internal gap of the structure. This research aims at developing a porous box-type breakwater consisting of a matrix of tubes or pipes running through the modular unit. The proposed breakwater is regarded as a sustainable structure providing a certain degree of wave protection to the coastal facilities.

\footnotetext{
* Corresponding author: heemin.teh@utp.edu.my
} 


\section{Literature review}

Breakwaters are often used to provide protection to beaches from excessive erosion. It is undoubtedly the breakwaters offer supreme wave attenuation performance and keep the shoreline protected. However, the damages they cause to the environment should not be overlooked. These include creation of increased wave activity in front of the structures due to excessive wave reflection, downcoast erosion, water contamination and disturbance to the marine ecosystem [3, 4]. The conventional type of breakwaters used for protection of the coast against wave action is the rubble-mound type (USACE, 1984) which uses rocks or concrete blocks for its construction and the employ of either material is aggressive to the environment. [5]. The construction of these gigantic structures requires a large amount of construction materials, e.g. sand, rocks of different sizes and concrete armor units that make the construction procedures extremely challenging especially when operating in the ever dynamic sea state.

At sensitive sites where construction of rubble mound breakwaters is not an option, rapidly installed modular breakwaters may be a viable alternative for providing wave sheltering function [6]. These modular breakwater units are pre-fabricated at onshore sites and towed or transported to the offshore construction sites by tugboats or barges. Free surface breakwater is regarded a kind of the modular breakwater. Teh classified the free surface breakwaters into four types, namely the box-type, plate-type, caisson-type and multipart-type [7]. Apart from these, a number of the modular breakwaters are rested on the seabed or the low crested rubble mound structures, e.g. reef balls, porous foundations; for increased efficiency of energy dissipation [8]. Most of these breakwater units intercept the waves by reflection, resulting in wave amplification near the structure. This may pose navigation hazards to the small floating vessels especially during the attack of storm waves.

Porosity is one of the major factors controlling the wave reflectivity of the breakwater [9]. In general, less porous breakwaters tend to yield high wave reflection [10]. On the other hand, breakwaters of large porosity are potentially effective wave energy dissipaters [11]. To ensure cost efficiency of the breakwater construction, many researches were conducted with the aim to determine the optimum design of breakwaters via both experimental and numerical approaches. Wu et al. suggested geometrical requirement for a single vertical porous plate with a horizontal plate [12]. Shih investigated wave attenuation performance of the porous perpendicular pipe breakwaters [2]. Manoharan et al. studied the wave transmission of a modular submerged breakwaters consisting of multiple pipes under regular waves [13]. They claimed that the sloping front face of the breakwaters helped in promoting wave breaking and energy dissipation. Koley and Sahoo studied the effect of porosity on energy dissipation of a semicircular submerged breakwater [14].

All oil and gas pipelines have specific design life spans. Upon attainment of the full design life cycle, the pipelines have to be decommissioned and removed so as to prevent from posing a threat to marine wildlife and navigation [15]. These pipelines can be modified and reused instead of being transported for disposal [16]. In this study, an attempt is made to adopt the used pipelines (or tubes) as the main construction material in a box-type breakwater. This research aims at developing a porous box-type breakwater consisting of a matrix of tubes or pipes running through the modular unit. The proposed breakwater is regarded as a sustainable structure providing a certain degree of wave protection to the coastal facilities.

\section{Methodology}

\subsection{Test model}

In this research, the porous box-type breakwaters of different geometries were developed to evaluate their hydraulic effectiveness with respect to (i) the breakwater porosity and (ii) breakwater width in wave approaching direction. This hydraulic investigation is important in determining the optimum design of the porous breakwater in terms of porosity and breakwater width. This paper will suggest some useful design criteria for porous box-type breakwater.

The porous box-type breakwaters were modelled according to the limitation of the test facilities, i.e. wave flume and wave generator. Based on the type of test parameter, the experiments undertaken for this study are clustered into two phases, i.e. Phase 1 and 2. Both phases investigate the hydraulic performance of the test models corresponding to the variations of breakwater porosity and model length respectively. Each standard test model designated for Phase 1 experiment was $0.32 \mathrm{~m}$ in length, $0.50 \mathrm{~m}$ in width and $0.48 \mathrm{~m}$ in height. A group of PVC pipes of different diameters for different factors of porosity and matrix arrangement (i.e. $9 \times 6$ ) ran through the full length of the test model horizontally. These tubes were supported by four internal plates, as shown in Fig. 1, to enhance the stability of the structure when exposed to wave environment. 


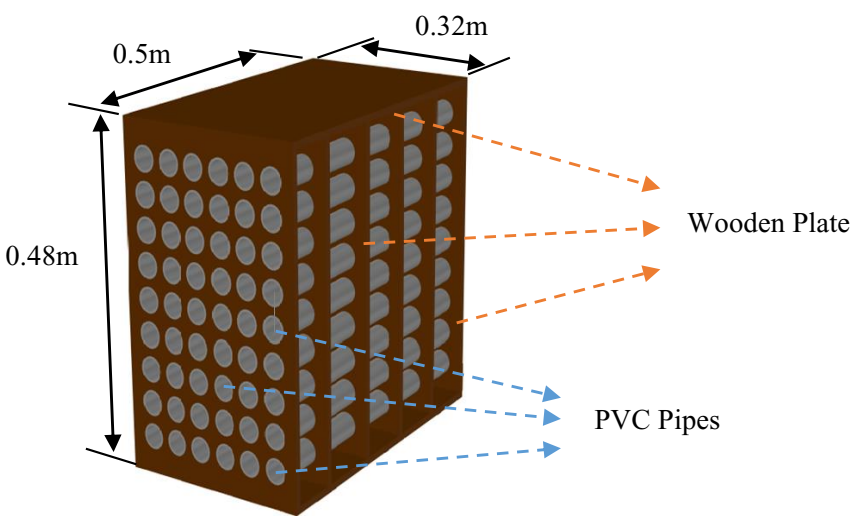

Fig. 1. Schematic drawing of the porous box-type breakwater test model.

The model was fabricated using wooden planks and PVC pipes with variations of porosity and tube length as given in the test paramters as shown in Table 1 for each phase. The aim of this experiment is to identify the optimum width of the breakwater unit that provides the desired hydraulic efficiency. A total of 8 test cases were set for this study to determine the optimum design of the porous box-type breakwater. The summary of the test parameters is depicted in Table 1. All test models were positioned perpendicular to the wave approaching angle and were anchored to the bottom by its effective mass. The mass of the test models was added by some weights placed on the top.

Table 1. Test parameters.

\begin{tabular}{|c|c|c|}
\hline Experiment ID & Breakwater Geometry & Test Parameters \\
\hline Phase 1 & Porosity $(\Phi / \%)$ & $29.91,34.15,34.91,37.24$ \\
\hline Phase 2 & Tube length $(l / \mathrm{m})$ & $0.25,0.50,0.75,1.00$ \\
\hline
\end{tabular}

\subsection{Experimental setup}

Two series of experiments denoted as Phase 1 and Phase 2 experiments were conducted in the 12-m long, 0.32-m wide and $0.50-\mathrm{m}$ high wave flume at the Hydraulic Laboratory of Universiti Teknologi PETRONAS, Malaysia. The wave flume constructed by transparent glass panels is furnished with a flap-type wave paddle at one end and a wave absorber at the other end. The wave flume is supported by a steel frame elevated $1.3 \mathrm{~m}$ above the floor level. The wave generator is capable of generating regular waves of different periods and heights in wave only condition. Whereas, the wave absorber is used to reduce the reflected waves on the wave flume.

The wave transmission, wave reflection and energy dissipation abilities of the test models were explored with respect to breakwater porosity, tube length and internal gaps between the porous breakwaters. The test models were examined under regular waves of wave period, $T$ of 0.8 to $2.0 \mathrm{~s}(\Delta T=0.1 \mathrm{~s})$ at water depth, $d$ of $25.0 \mathrm{~cm}$. This yields a range of wave steepness, $H i / L$ varied from 0.005 to 0.080 , where $H i$ and $L$ are the height and length of the incident waves respectively. The laboratory set-up of the experiment is shown in Fig. 2. Three wave probes were placed at seaward of the test models for measurement of incident waves and reflected waves from the structure, and the other three wave probes placed at the shoreward to record the transmitted waves. The wave probes were connected to a data logger which gauges the readings from the wave probes and transmits the data to the PC for further analysis. All wave probes were carefully calibrated against systematic errors prior to the experiments. In total, approximately 104 tests were conducted for this experimental study. 


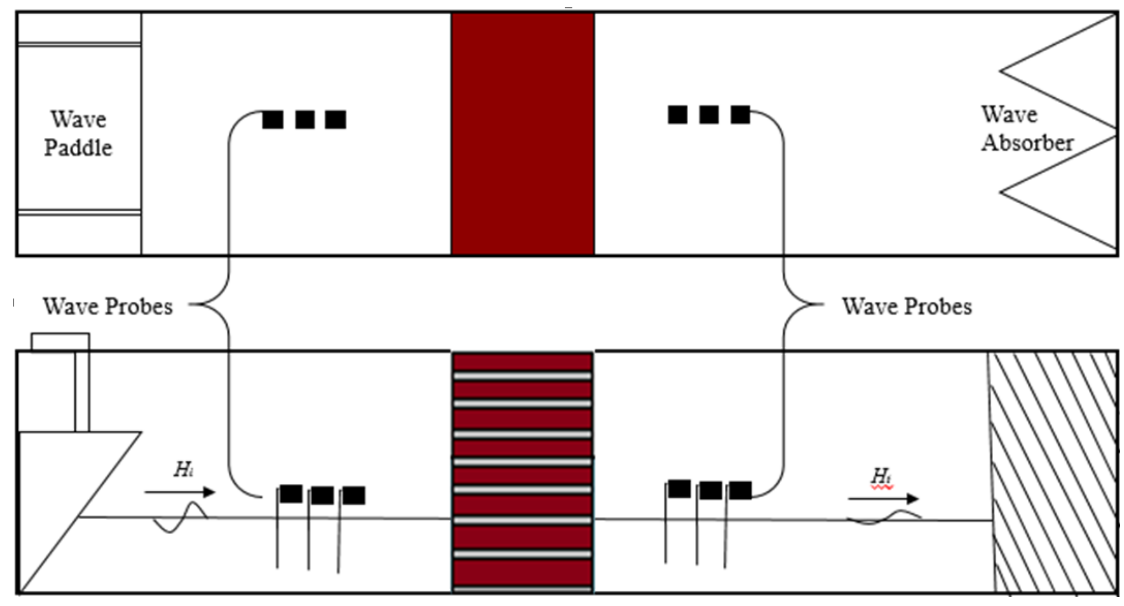

Fig. 2. Experimental setup

\section{Results and discussions}

Hydraulic performance of the breakwaters was evaluated by the energy coefficients, which comprises transmission coefficient $\left(C_{T}\right)$, reflection coefficient $\left(C_{R}\right)$ and energy loss coefficient $\left(C_{L}^{2}\right)$ :

$$
\begin{aligned}
& C_{T}=H_{T} / H_{I} \\
& C_{R}=H_{R} / H_{I} \\
& C_{L}{ }^{2}=1-C_{T}{ }^{2}-C_{R}{ }^{2}
\end{aligned}
$$

where $H_{I}, H_{T}$ and $H_{R}$ are incident, transmitted and reflected wave heights, respectively. The wave energy coefficients $C_{T}, C_{R}$ and $C_{L}^{2}$ are plotted against the relative breakwater width, $B / L$ where $B$ and $L$ are the breakwater width and the wavelength corresponding to the wave period $T$, respectively. These energy coefficients were also individually evaluated with respect to the breakwater porosity $(\Phi)$ and the relative tube length $(h / l)$, where $h$ is breakwater height and $l$ is tube length. The optimum values of these parameters were selected as the design parameters for the porous breakwater considering the provision of low transmission and high energy loss at the structure.

\subsection{Effect of breakwater porosity, $\Phi$}

Fig. 3 displays the coefficient of transmission $C_{T}$ for the porous breakwaters subjected to porosities of 29.91, 34.18, 34.91 and $37.24 \%$ in regular waves of steepness ranging from 0.05 to 0.08 . The $C_{T}$ values are plotted against the relative breakwater width, $B / L$ in the figure. It can be observed from the figure that the $C_{T}$ values of the tested porous breakwaters gradually decrease from 0.4 to 0.1 with an increase of $B / L$ from 0.10 to 0.23 . Further increase of $B / L$ beyond 0.23 does not seem to help in bringing down the $C_{T}$ values appreciably. This signifies that improvement of wave attenuation performance of the breakwaters with porosity ranging from 29.91 to $37.24 \%$ is valid only at $0.1<B / L<$ 0.23 . It is not advisable to construct the breakwater beyond $B / L=0.23$ as the size of the breakwater does not affect the wave attenuation efficiency.

In terms of the breakwater porosity, it can be seen from Fig. 3 that the $C_{T}$ variation of the breakwaters with $\Phi=$ $29.91,34.18$ and $34.91 \%$ is almost invisible indicating that wave attenuation is less affected by the change of breakwater porosity at $30 \%<\Phi<35 \%$. As the breakwater porosity further increases to $37.24 \%$, it is observed that the transmitted waves recorded at the leeside of the breakwater are higher than those waves recorded at the breakwaters of lower porosities by the order of two. Nevertheless, the influence of breakwater porosity on $C_{T}$ becomes weak again at $B / L<0.23$. Considering its excellent wave suppression ability up to $90 \%$ wave attenuation and cost optimization of breakwater, it is recommended the porous breakwater to be designed at $B / L=0.23$. 


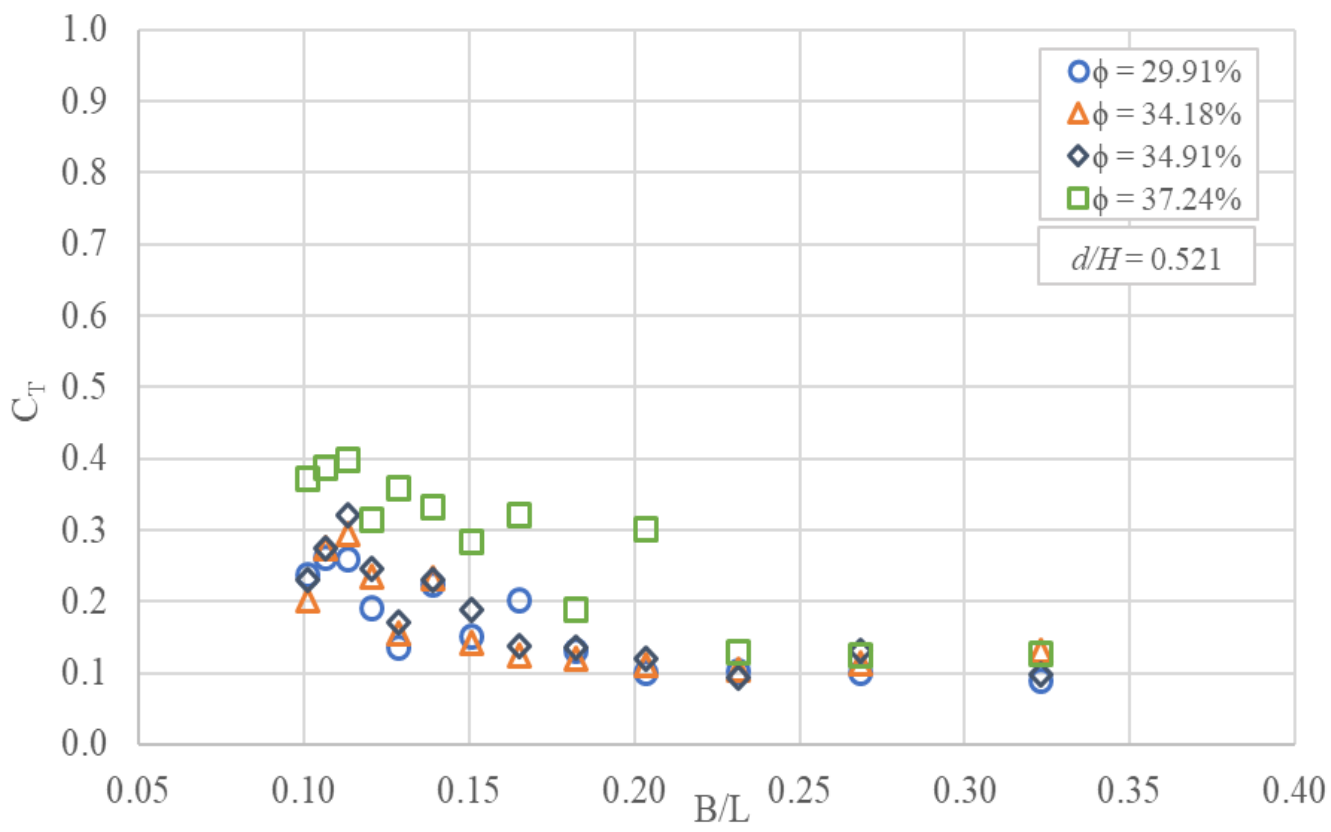

Fig. 3. Effect of breakwater porosity on $C_{T}$

The effect of relative breakwater width on $C_{R}$ of the test models of $\Phi=29.91,34.18,34.91$ and $37.24 \%$ is demonstrated in Fig. 4. Overall, the $C_{R}$ variations of the test models of different porosities with the change of $B / L$ are relatively small, giving mean $C_{R}$ values of $\Phi=29.91,34.18,34.91$ and $37.24 \%$ as $0.75,0.70,0.68$ and 0.60 , respectively. The finding is sensible as breakwaters of lower porosity are more reflective in nature and the impermeable solid flat surfaces are capable of making the incident wave rebound seaward without much transmission through the internal pipes running through the structures. As suggest by Equation (3), wave attenuation performance of the porous breakwater is governed by the reflective and energy dissipative efficiency of the structure. Increased wave reflection would contribute to reduction of transmitted waves at the leeside of the breakwater. Selection of breakwaters of lower porosity (i.e. $\Phi=29.91 \%$ ) for wave protection may be a viable option if the construction site can tolerate with the presence of the reflected waves that would potentially lead to excessive wave agitation at the front of the structure. Else, breakwater of larger porosity should be opted; however, breakwaters of $\Phi>35 \%$ is not recommended due to transmission of excessive wave energy to the leeside (see Fig. 3). Within the test limits of the current experiments, the most optimum porosity proposed for the breakwater is $34-35 \%$.

The plots of energy dissipation $C_{L}^{2}$ of the breakwater with porosities of $29.91,34.18,34.91$ and $37.24 \%$ corresponding to $B / L$ are presented in Fig. 5. Overall, $C_{L}{ }^{2}$ of the test models agitate at some degree as $B / L$ increases from 0.10 to 0.32 . The breakwaters of $\Phi=34.18,34.91$ and $37.24 \%$ exhibit the highest $C_{L}^{2}$ values $\left(C_{L}^{2} \approx 0.7\right)$ at the optimum $B / L=0.23$. This denotes that the porous breakwater of $B / L=0.23$ reduce wave energy primarily by dissipation rather than by wave reflection. This hydraulic property of the porous breakwater is highly desirable. Further, it can also be observed from Fig. 5 that $C_{L}^{2}$ values of the breakwater of $\Phi=29.91 \%$ are relatively low compared to those of the breakwaters of higher porosities. The $C_{L}^{2}$ variations of the breakwaters of $\Phi=34.18,34.91$ and $37.24 \%$ with $B / L$ are somewhat marginal. Hence, a porosity ranging between 34 and $37 \%$ should be adopted if the breakwater is aimed to be designed as an effective energy dissipater. In developing of a hydraulically efficient (i.e. low wave transmission, low wave reflection and high energy dissipation), it is recommended to set the geometry and porosity of the breakwater to be $B / L=0.23$ and $\Phi=35 \%$, respectively. 


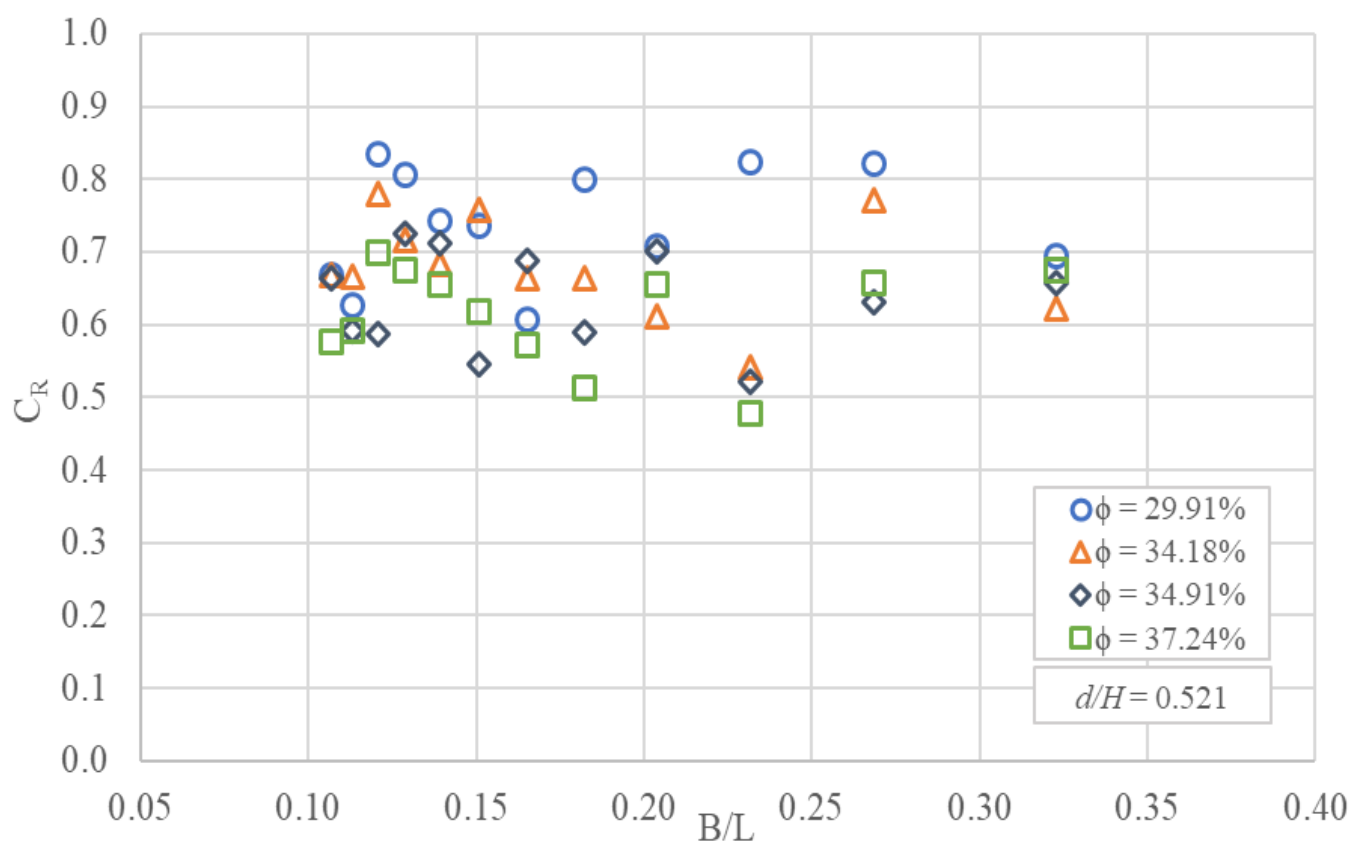

Fig. 4. Effect of breakwater porosity on $C_{R}$

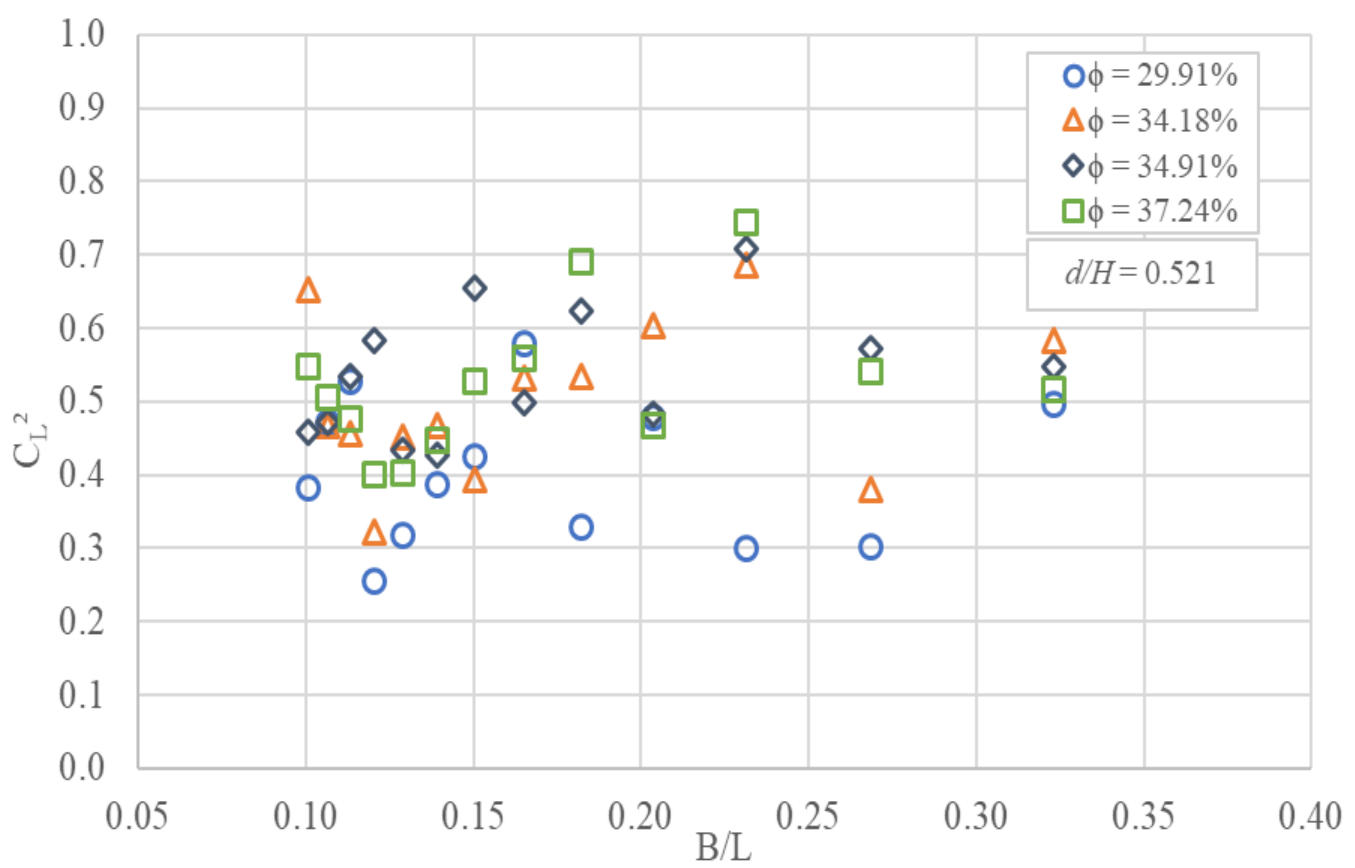

Fig. 5. Effect of breakwater porosity on $C_{L}^{2}$

\subsection{Effect of tube length, $h / l$}

Besides breakwater porosity, the length of the internal tubes running within the breakwater block is regarded as one of the major factors affecting hydraulic properties of the breakwater studied in this project. Fig. 6 presents the $C_{T}$ of the breakwaters with an optimum porosity of $35 \%$ (see Section 3.1), in which the embedded tube lengths, $l$ were set at 0.25 , $0.50,0.75,1.00 \mathrm{~m}$, yielding relative breakwater length, $h / l$ (where $h$ is the height of the test models) of $1.92,0.96,0.64$ and 0.48 , respectively. It is apparent from the figure that both effects of $B / L$ and $h / l$ on $C_{T}$ are prominent, i.e. the $C_{T}$ values 
decrease with an increase in $B / L$, and with a decrease in $h / l$. The $C_{T}$ relations with $B / L$ are in good agreement with those illustrated in Fig. 3, where the $C_{T}$ of $h / l=0.48,0.64$ and 0.96 remain in plateau as $B / L>0.23$.

It is, once again, verified that $B / L=0.23$ the optimum geometrical design parameter of the porous breakwater proposed for this study as long as $h / l<1$. At $h / l>1.92$, the $C_{T}$ of the test model has the tendency to further decrease when $B / L$ is beyond the optimum value, i.e. $B / L=0.32$. It is learnt from the figure that increasing the length of the internal tubes does help in enhancing the wave dampening ability of the porous breakwater when subjected to regular waves. For instance, the breakwater of $h / l=0.48$ (i.e. the height of the breakwater is almost half of the internal tube length) exhibits wave suppression ability as high as $95 \%$. Despite the superior wave attenuation ability, the breakwater of small $h / l$ would result in increased material cost due to the tube extension. Hence, sensible $h / l$ ratio for the breakwater design must be determined with reference to the corresponding $C_{R}$ and $C_{L}^{2}$ behaviours.

Wave reflection coefficient of the test models of $h / l=0.48,0.64,0.96$ and 1.92 corresponding to $B / L$ is demonstrated in Fig. 7. From the figure, a slight fluctuation of $C_{R}$ is seen for the respective $h / l$ plots. Overall, it can be observed that attainment of minimum $C_{R}$ takes place at $0.20<B / L<0.25$. In another word, the reflective ability of the breakwater of the optimum geometry, i.e. $B / L=0.23$, is relatively low and it should behave as a good anti-reflection structure. Apart from this, it can also be observed from the figure that the breakwaters of longer tubes tend reflect the wave energy more. At $h / l=0.48$, the highest $C_{R}$ recorded is 0.83 . The observation can be explained by the fact that the water entrained within the sufficiently long tubes that potentially restricts and delays the passage of water flow in the tubes. The 'water choking effect' poses obstructions to intercept the incoming waves, which in turn resulting in rebound of wave energy to the seaward direction. Another drawback of extended breakwater tube are high material cost and increased installation difficulty.

Fig. 8 shows the plots of energy dissipation of test models of $h / l=0.48,0.64,0.96$ and 1.92 with respect to $B / L$. In most test cases of $h / l$, the maximum $C_{L}^{2}$ attained at $0.20<B / L<0.25$ have confirmed the effectiveness of the breakwater with $\Phi=34.91 \%$ in dissipating the wave energy. From the figure, it can be seen the $C_{L}^{2}$ data points of the respective $h / l$ are closed related to each other, signifying that the energy loss of the test models is less dependent upon the relative tube length. Therefore, wave attenuation by energy dissipation within the extended breakwater tubes does not seem to be obvious in this study.

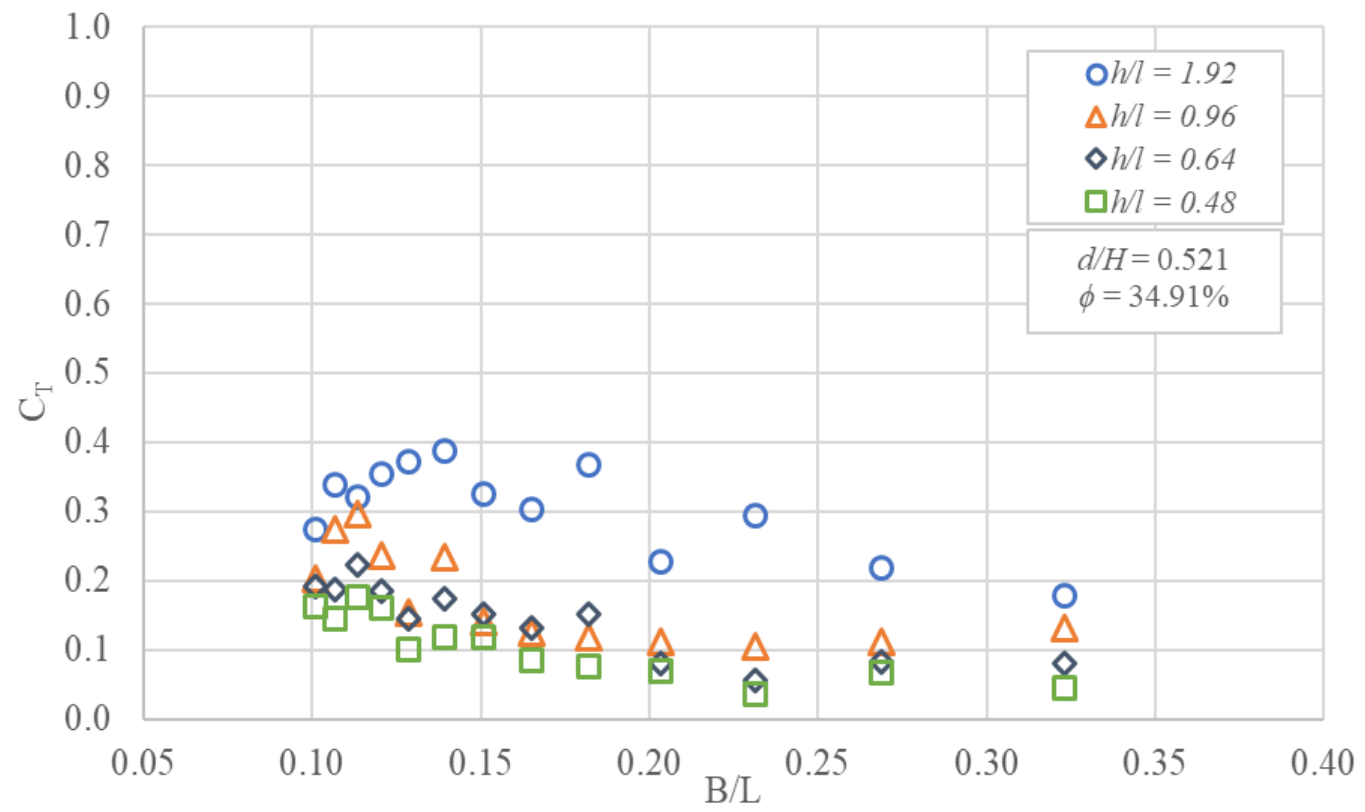

Fig. 6. Effect of relative tube length on $C_{T}$ 


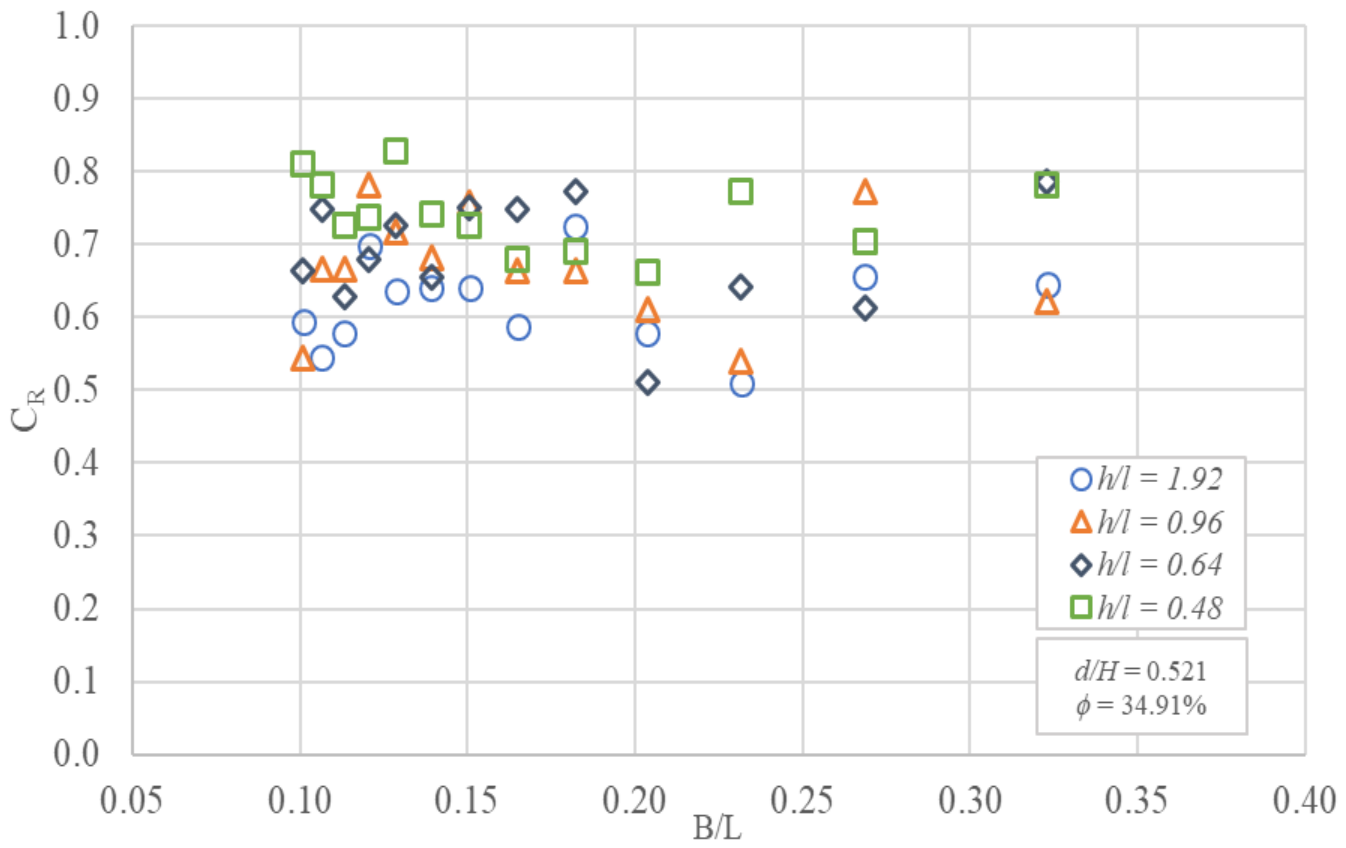

Fig. 7. Effect of relative tube length on $C_{R}$

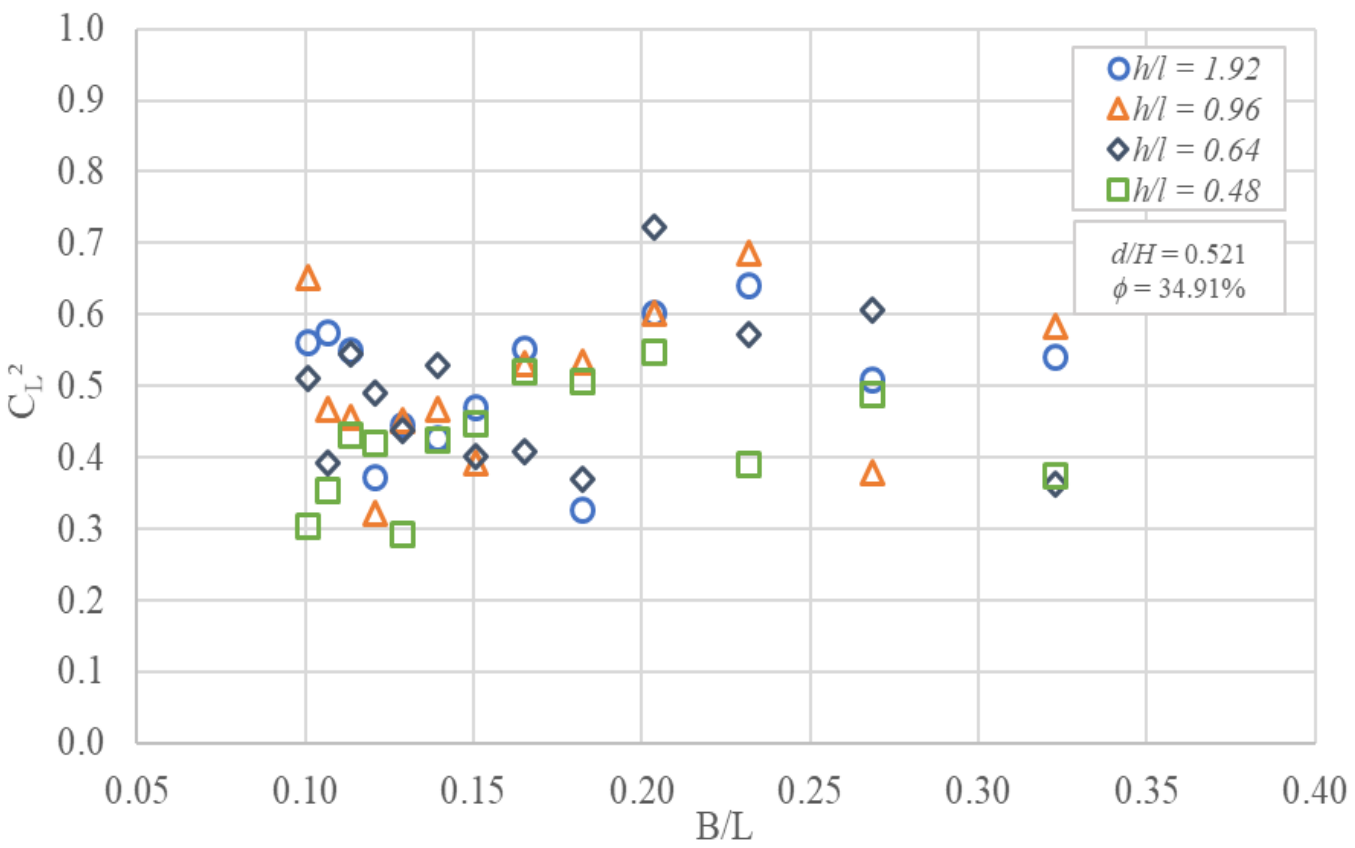

Fig. 8. Effect of relative tube length on $C_{L}^{2}$

Based on the inputs given in Figs. 6, 7 and 8, it is wise to use higher $h / l$ ratio to design the geometry of the internal breakwater tubes. Nevertheless, the breakwater of $h / l=1.92$ is considered geometrically instable due to its slenderness when interacting with intense waves. Instead, the breakwater of $h / l \approx 1$ is recommended mainly due to the economical factor. The breakwater serves as a reasonably good wave attenuator and anti-reflection structure as well as an effective energy dissipater. The hydraulic efficiencies are about $10 \%$ short of those of the breakwater of $h / l=0.64$. 


\section{Conclusions}

A systematic test program was undertaken to determine the optimum breakwater geometry that provides good hydraulic performances, i.e. low wave transmission and reflection, and high energy dissipation. The following conclusions were reached within the limitation of this study:

- The hydraulic performances in terms of wave transmission, wave reflection and energy dissipation are controlled by the porosity $(\Phi)$, relative breakwater width $(B / L)$ and relative breakwater tubes $(h / l)$.

- Hydraulic performances of the breakwater are optimized when designed at $B / L=0.23$ and $\Phi=35 \%$. From the experimental results, the breakwater was capable of reducing the design wave height by $90 \%$, and limiting the energy reflected from the structure to about $25 \%$. The maximum energy dissipated at the structure was about $70 \%$.

- In terms of the breakwater tube length, the breakwater is recommended to be designed at $h / l \approx 1$ mainly due to the economical consideration. The breakwater of $h / l \approx 1$ is anticipated to be a reasonably good wave attenuator and anti-reflection structure as well as an effective energy dissipater.

This research is funded by Yayasan Universiti Teknologi PETRONAS under the project vote 0153AA-E95. The authors would like to thank the laboratory technologist - Mr. M. Zaid b Zainuddin for his technical assistance.

\section{References}

1. Laju, K., V. Sundar and R. Sundaravadivelu, "Hydrodynamic characteristics of pile supported skirt breakwater models." Applied Ocean Research 33(1): 12-22. (2011)

2. R.S. Shih, W.K. Weng and C.R. Chou, "The performance characteristics of inclined highly pervious pipe breakwaters." Ocean Eng. Vol 100: 54-66. (2015)

3. H. M. Teh, and V. Venugopal, "Optimization of Hydraulic Efficiency of a free surface semicircular breakwater using wave screens." The $34^{\text {th }}$ International Conference on Ocean, Offshore and Arctic Engineering (OMAE2015) (2015)

4. R. Yaacob, E. H. Ariffin, "Effects of Sedimentology and Beach Morphology on Tourism at Terengganu Beach Malaysia." UMTAS (2010)

5. K. Vieira, L. K. Girelu, and T. Zenker, "Development of a Green Floating Breakwater with Re-use of PET Bottles." Journal of Sustainable Development 5(12). (2012)

6. H. M. Teh, "Wave transmission over a submerged porous breakwater: An experimental study." App. Mechs and Materials, vol. 567, pp. 319-324. (2014)

7. H. M. Teh, "Hydraulic performance of free surface breakwaters: A review. Journal of Sains Malaysian, 42(9), pp. 1301-1310 [ISI \& SCOPUS indexed]. (2013)

8. L. E. Harris, "Artificial Reefs for Ecosystem Restoration and Coastal Erosion Protection with Aquaculture and Recreational Amenities.” ASR Conference. (2006).

9. S. Das, S.N. Bora, "Reflection of oblique ocean water waves by a vertical porous structure placed on a multi-step impermeable bottom.” Applied Ocean Research, Vol 47, pp 373-385. (2014)

10. M. Muttray, H. Oumeraci, E. T. Oever, "Wave Reflection and Wave Run-up at Rubble Mound Breakwaters." $4314-$ 4324. (2007)

11. J. Wu, Z. Wan, Y. Fang, "Wave reflection by a vertical wall with a horizontal submerged porous plate." Ocean Eng. Vol 25(9): 767-779. (1998)

12. R. S. Shih, "Experimental study on the performance characteristics of porous perpendicular pipe breakwaters." Ocean Eng. Vol 50: 53-62. (2012)

13. L. S. Manoharan, H. M. Teh, and C. H. Lim, "Wave transmission of a submerged breakwater consisting of multiple pipes". APRN J. of Eng. App. Sciences, Vol. 12, No 20, Asian Research Publishing Network, pp. 5807-5810. (2017)

14. S. Koley, and T. Sahoo, "Wave interaction with a submerged semicircular porous breakwater placed on a porous seabed." Engineering Analysis with Boundary Elements 80: 18-37. (2017)

15. M. J. Kaiser, "FERC pipeline decommissioning cost in the U.S. Gulf of Mexico, 1995-2015." Marine Policy 82: 167-180. (2017)

16. N. A. Zawawi, M. S. Liew and K. L. Na, Decommissioning of offshore platform: A sustainable framework: $26-31$. (2012) 